\title{
Effect of Logistics Practices on Operational Performance: A Case Study of Arjo Didesa Sugar Factory, Oromia, Ethiopia
}

\author{
Desta Faltaso Mena Legesse Lemma Chuma \\ Lecturer, Department of Management, Kebri Dehar University, Ethiopia
}

\begin{abstract}
The purpose of this study was to investigate the effect of logistics practice on operational performance of the Arjo Didesa Sugar Factory. Therefore, explanatory research design with both qualitative and quantitative approach was used in order to explain the effect of logistics practices on operational performance. The sample of 219 respondents from Arjo Didesa sugar factory working in factory operation and supply and facility management was taken for the study and out of these, data were obtained from 186 respondents. A stratified random sampling technique was employed; in which the target population is stratified and then, sample was randomly selected from each stratum. In addition to these techniques, purposive sampling was applied for the interview of the managers of respective department. Here, both primary and secondary sources of data were used for addressing the stated research questions according to their nature. Structured questionnaire and semistructured interview were used to gather data. Mean is employed in order to summarize and describe quantitative information. Regression analysis was used to analyze the effect of logistics practices on the operational performance and correlation analysis was also used to determine the relationship between variables. The findings of the study revealed that transportation and inventory management have high significant positive effect on operational performance even though procurement practice, information flow and warehousing have positive significant effect on operational performance. In order to improve operational performance of the factory, researcher recommend to Arjo Didesa sugar factory to upgrade investment on infrastructure for transportation of raw materials within factory. Researcher also initiated to provide recommendation on using principle of economic order quantity that enable effective inventory management.
\end{abstract}

Keywords: Logistics, Logistics practices, Operational performance, and Sugar Factory.

DOI: $10.7176 /$ IEL/10-4-01

Publication date:May $31^{\text {st }} 2021$

\section{Introduction}

\section{Background of the Study}

Logistics is the process of planning, implementing and controlling the efficient, cost effective flow and storage of raw materials, in-process inventory, finished goods and related information from point of origin to point of consumption for the purpose of conforming to customer requirements (Donald, 2003). Logistics encompasses all of the information and material flows throughout an organization. It includes everything from the movement of a product or a service that needs to be rendered, through to the management of incoming raw materials, production, the storing of finished goods, its delivery to the customer (Wisner, Tan \& Leong, 2012).

According to (Ghiani, Laporte, Musmanno, 2004), Logistics is one of the most important activities in modern societies. A few figures can be used to illustrate this assertion. It has been estimated that the cost incurred for logistics practices by USA organizations in 1997 was 862 billion dollars, corresponding to approximately $11 \%$ of the USA Gross Domestic Product (GDP). This cost is higher than the combined annual USA government expenditure in social security, health services and defense. These figures are similar to those observed for the other North America Free Trade Agreement (NAFTA) countries and for the European Union (EU) countries. Thus, logistics practices represent a significant part of a company's operations.

Africa continent was not performing well in logistics compared to other continents as the report confirmed that the top four countries were from Europe, the fifth one was from Asia however, the bottom five were all from Africa. Especially in Sub-Saharan African countries, the infrastructures were poorly managed and maintenance was lacking. Consequently, inefficient transport and communication formed a major obstacle in achieving efficiently organized flows of goods and services. As cited by (W. Mwangi \& T. Nyambura, 2015).

Ethiopian logistics system is also characterized by poor logistics management system and lack of coordination of goods transport, low level of development of logistics infrastructure and inadequate fleets of freight vehicles in number and age, damage and quality deterioration of goods while handling, transporting and in storage. This coupled with lack of sea port resulted in poor linkage of producers (farmers) to the consumers(market) and non-competitiveness of Ethiopian goods on global market (Fekadu, 2013).

Logistics practices have great effect on operational performance, For instance; the advent of information technology (IT) revolutionizes logistics operation and Poor logistics performance reflects the firm's information capability which impacts operational performance (Shang, K.-C., \& Marlow, P. B. , 2007).

More over procurement practices also integrates various firm's operations and support functions, 
synchronizing production with new orders, purchasing with demand, scheduling and shipping with customer requirements (Kiare, 2015). The inventory management also affects the operational performance, as too much inventory consumes physical space, creates a financial burden, and increases the possibility of damage, spoilage and loss (Nyabwanga, \& Ojera., 2012). On the other hand, too little inventory often disrupts business operations (Dimitrios, 2008). Lastly, the operation of transportation determines the efficiency of moving products (W. Mwangi \& T. Nyambura , 2015). In addition warehousing is an integral part of the company operations in that an inadequate goods acceptance and receipt, storage and retrieval or picking affect operational performance of manufacturing firms (Emmett, 2005). However, in Arjo Didesa Sugar Factory there has been knowledge gap as to whether these factors can affect operational Performance.

Likewise, it as a researchable gap and required to investigate logistics practice of ADSF with desire to assess how these practices affect operational performance, to show advantage of having efficient logistics management on operational performance of the factory, this initiated the researcher to conduct research on effect of logistics practice on operational performance of the Arjo Didesa Sugar factory to investigate how these practices influence the operational performance of the factory.

\section{Problem Statement}

Sugar is an important commodity and there are numerous challenges and opportunities that exist in Africa as a whole for sugar industry. Most Sub -Saharan Africa countries still heavily rely in the agricultural sector as a source of economic livelihood for most of its population. Hence, in an effort to improve the sector, various interventions have been adopted (Miller, 2008).

According to (Ethiopia investment agency, 2016), the current annual domestic supply of sugar in Ethiopia is between 6 to 6.5 Million Quintals of which 3.25 to 4 Million Quintals of sugar are produced domestically while the rest is imported to fill the gap. And, to do away with above trend, the Government has put the sugar industry sub sector as one among other mega manufacturing industry sectors which have got great attention in the GTP.

Accordingly, the Government is currently carrying out huge sugar development projects to eliminate the gap between demand and supply of sugar domestically. However the entrance of Arjo Didesa, Kessem and Tendaho sugar factories into operation could not narrow the unmatched domestic demand and supply relations of the sugar product (Ashenaf, 2016). This is because of the operational performance of sugar factories in Ethiopia is low and they have many factors of disadvantage from farming, harvest and transportation management, warehousing, inventory management, information flow and procurement practice (Kedir, 2013). In addition, Arjo Didesa sugar factory is one of the least in operational performance among sugar factories in Ethiopia (Annual report, 2016). Therefore this research aimed to investigate the effect of logistics practice on operational performance in the line with performance flexibility and lead time.

\section{Research Questions}

This study addressed the following research questions;

- How transportation management affect operational performance of Arjo Didesa sugar factory?

- What is effect of information flow on operational performance of Arjo Didesa sugar factory?

- How inventory management activities affect operational performance of Arjo Didesa sugar factory?

- What is the effect of procurement practice on operational performance of Arjo Didesa sugar factory?

- What is the effect of warehousing on operational performance of Arjo Didesa sugar factory?

\section{Objectives of the study}

- To investigate effect the of transportation management on operational performance of Arjo Didesa sugar factory.

- To assess the effect of information flow on operational performance

- To analyze how inventory management activities affect operational performance of Arjo Didesa sugar factory

- To investigate the effect of procurement practice on operational performance

- To assess the effect of warehousing on operational performance

\section{Review of Related Literature}

This part of the study address relevant conceptual, theoretical framework and empirical review related to the topic of the study. The Resource-Based View theory explicitly looks for the internal sources of sustained competitive advantage and aims to explain why firms in the same industry might differ in performance. (Peteraf, M., \& Barney, J., 2003). In game theory, horizontal cooperation in logistics was proved efficient to reduce global cost and improve the performance level of the firm (Cruijssen. F., Cools. M., \& Dollaert. W., 2007). Theory of Constraints views organizations as systems consisting of resources, which are linked by the processes they 
perform. The goal of the organization serves as the primary judge of success. Within that system, a constraint is defined as anything that limits the system from achieving higher performance relative to its purpose (Moore, 1998). Therefore, this study considers logistics practices as constraints that hinder the factory from achieving higher performance.

The study result of ( Mokogi; Mairura; \& Ombui, 2015) Shows that procurement practices have effect on operational performance. For instance, the study revealed that the process mainly resulted in listing of general and unspecialized suppliers or "briefcase suppliers" contributing greatly to poor performance. The study findings also revealed that poor management of procurement processes including planning, budgeting, length of time involved, use of quotations and subcontracting directly led to inefficiencies which led to missed targets and eventual poor performance. According Nsikan Efiok John, John Joseph Etim and Tommy Uduak Ime, 2015, findings revealed significant differences between effective management of inventory and optimal operating performance. For instance, while firms that scientific inventory management approaches reported efficiency in capacity utilization, increased service level, and reduced lead time, others with unscientific strategies had minimal utilization of material resources. According to (Lipaj, D., \& Davidaviciene, V., 2013), the impacts of information flow are categorized into two groups: tangible and intangible. The tangible impact include; improved performance, reduced operational costs, increased profits, improved resource utilization, reduced general administrative costs, reduction in waste whereas the intangible impacts include; enhanced teamwork, standardization, improved cost structure, improved information visibility, improved management decision making process, improved morale, people development, greater flexibility, integration, internal improvement. The study by (Mwangangi, 2016) established that firm performance was significantly influenced by transport management. The study finding of (Mukolwe, 2015) indicate that automation of warehousing enhances accuracy, reduces wastages and enhances speed of operations thereby improving warehouse efficiency. Adequate storage facilities with modern handling tools are necessary to ensure continuous supply of raw materials and correct handling of stored materials. It also ensures guarantee in quality.

\section{Conceptual Framework}

There are around eleven logistics practices that affect firm's operational performance even though some authors bring it into five or seven practices by merging activities performed in the same destination and immediately before reaching the destination. The employees and respective managers of departments were vital in providing data on five logistics management practices such as transportation, information flow, inventory management, warehousing and procurement, therefore in this study, researcher investigated the effect of transportation, information flow, inventory management, warehousing and procurement practices on operational performance in line with operational flexibility and lead time.

\section{Methods and Materials}

This study employed explanatory design with both quantitative and qualitative research approach as the study aims to explain the effect of logistics practice on operational performance. The target populations for this study are 482 employees of Arjo Didesa Sugar Factory working in Factory operation and Supply and Facility management department because these departments are more concerned with topic of the study. The sampling frame was the lists of 482 employees working in factory operation and supply and facility management department which is resulted from taking all employees from factory operation department and excluding fixed property preservation and security team as members of this team may be considered to have lesser knowledge about topic of the study. 


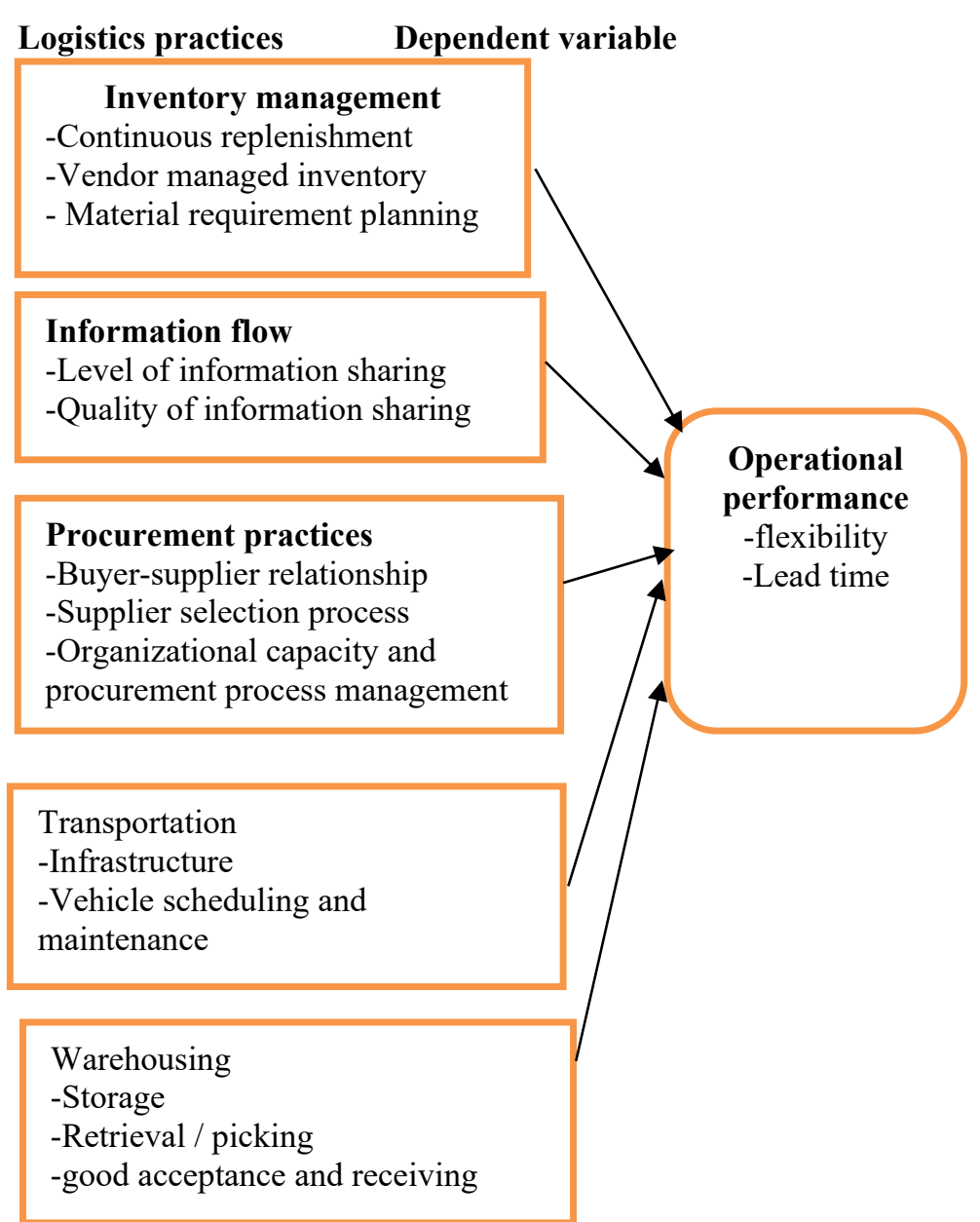

The sample of respondents was selected from the sampling frame as shown in the table below.

\begin{tabular}{|l|l|l|}
\hline Name of selected departments & Number of employees & Selected sample size \\
\hline Factory operation & 410 & 186 \\
\hline Supply chain and Facility management & 72 & 33 \\
\hline Total & $\mathbf{4 8 2}$ & $\mathbf{2 1 9}$ \\
\hline
\end{tabular}

In order to determine the sample size from total population, researcher used the following formula of Yamane, 1967 which asserts that the sample size can be determined by:

$$
\mathrm{n}=\mathrm{N} / 1+\mathrm{N}(\mathrm{e}) 2
$$

Where $\mathrm{N}=$ Target population

$\mathrm{e}=$ tolerance at desired level of confidence, at $95 \%$ level $(0.05)$

$\mathrm{n}=$ sample size

$$
\begin{aligned}
& =482 / 1+(482)(0.05) 2 \\
& =482 / 2.20 \\
& =218.594 \sim 219
\end{aligned}
$$

According (John, A, Robert, \& David, 2007) to answer how many items are selected from each stratum or how to allocate the sample size of each stratum, we usually follow the method of proportional allocation under which the sizes of the samples from the different strata are kept proportional to the sizes of the strata by dividing the total population of the size "N" into $\mathrm{K}$ strata of size $\mathrm{N} 1, \mathrm{~N} 2, \mathrm{~N} 3 \ldots \mathrm{NK}$ and take sample from each stratum randomly with the following sample size proportional allocation formula.

$\mathrm{Ni}=\mathrm{Ni} / \mathrm{N}^{*} \mathrm{n}$

Where $\mathrm{Ni}=$ total population of single strata

$$
\begin{aligned}
& \mathrm{I}=1,2,3 \ldots \mathrm{K} \\
& \mathrm{n}=\mathrm{n} 1+\mathrm{n} 2+\mathrm{n} 3 \ldots \mathrm{nk} \\
& \mathrm{n}=\text { total size of strata } \\
& \mathrm{N}=\text { total population }
\end{aligned}
$$

For Factory operation department, $\mathrm{n} 1=410 / 482 * 219 \quad=186.286 \sim \underline{186}$

For supply and Facility management department, n2 $=72 / 482 * 219=32.7136 \sim \underline{33}$

Therefore the researcher took 186 from Factory operation department out of 410, 33 from supply and facility 
management department out of 72 for questionnaires with total of 219 respondents. The sample size for this study was determined by adopting stratified random sampling where the population is grouped into stratus, because the researcher select respondents from concerning department for topic of the research.

This study basically depend on primary data in which the researcher prepared the questionnaires that were distributed to employees of Arjo Didesa Sugar Factory working in Factory operation and supply and facility management department. The secondary data was used only for supporting the finding obtained from analysis of primary data.

The researcher employed primary data which were collected through self-administered questionnaires with closed ended questions. As much as possible, a 5-point likert scale was used to investigate effect of logistics practice on the operational performance of Arjo Didesa Sugar Factory.

All research questions were analyzed with the help of Statistical Package for Social Science (SPSS) Version 20 that was used to aid in the analysis. In order to analyze the data, the two sets of Statistics: Descriptive and Inferential statistics was used. Descriptive statistics summarizes and describes quantitative information in the form of mean and percentage, whereas inferential statistics (multiple linear regressions and correlation) was taken from this tool.

The model built around two sets of variables, specifically dependent variable (operational performance) and independent variables (inventory management, transportation, information flow, warehousing, and procurement practice). The basic objective of using regression equation on this study is to make the study more effective at explaining, understanding and predicting the stated variables. The following regression model is formulated with five independent variables and one dependent variable.

$\mathrm{Y}=\beta 0+\beta 1 \mathrm{X} 1+\beta 2 \mathrm{X} 2+\beta 3 \mathrm{X} 3+\beta 4 \mathrm{X} 4+\beta 5 \mathrm{X} 5+£$

Where

$\mathrm{Y}=$ dependent variable $=$ operational performance

$\beta=$ coefficient

$\mathrm{X} 1=$ transportation, $\mathrm{X} 2$ = information flow, $\mathrm{X} 3$ = inventory management, $\mathrm{X} 4$ =procurement practices, $\mathrm{X} 5=$ warehousing

$£=$ error

The significance of the analytical model is checked by the use of ANOVA statistical model which is analysis of variance and a multiple linear regression analysis were done to find out the relationship between logistics practice and operational performance. A pilot study was conducted to refine the methodology and test instrument such as a questionnaire before administering the final phase. Questionnaires were tested on potential respondents to make the data collecting instruments objective, relevant, suitable to the problem and reliable as recommended by (John, A, Robert, \& David, 2007). Cronbach alpha coefficient was used to analyze the reliability or internal consistency of items and typically an alpha value of 0.67 or higher (Cohen et al. 2007: 506) is taken as a good indication of reliability. The reliability statistics revealed that Procurement practice has (0.729), Inventory management (0.682), Information flow (0.69), Transportation management (0.754), Warehousing (0.69) and Operational performance $(0.738)$ which indicate that the instruments are reliable and acceptable for further data analysis. In order to ensure the content validity, discussion with experts in area was made. Regarding the right to privacy of the respondents, all participants were briefed about the research and joined with their full consent, maintained the confidentiality of the identity of each participant and also the researcher reported the findings in complete honesty.

\section{Result and Discussion}

This Part presents the analysis and interpretation which carried out based on the data collected through questionnaire from respondents and interview made with managers of respective departments. From the total 219 questionnaire distributed to employees of Arjo Didesa sugar factory working in factory operation and supply and facility management department, only 186 questionnaires were returned and used for analysis that shows response rate of 84.9 percent. The study used descriptive statistics to present the frequency and the percentages of the gathered data on the effect of logistics practices on operational performance of Arjo Didesa Sugar Factory. The mean of respondents in each dimensions of logistics practice suggest that the average amount that in each dimension respondents agree, strongly agree, neutral, disagree and strongly disagree in their responses. The mean statistical values of the items were based on the 5 point Likert scale and illustrated through the following assumptions: if the mean (M) score is up to 2.99 it implies that the respondents ${ }^{\text {ee }}$ disagree with the statement, if the mean score is between 3-3.99 it indicates that the respondents ${ }^{\text {ee }}$ prefer to stay Neutral, and finally if the mean score is 4 and above it implies that the respondents ${ }^{\text {ee }}$ agree with the statement.

The factory is conducting several procurement practices in order to facilitate their operation such as maintaining strong buyer-supplier relations with its suppliers, regular sharing of critical supply chain information with its suppliers, conducting Supplier selection as per the act and regulations of procurement, Proper supplier prequalification process and filling skill gap of the procurement staff, but inadequate management of 
procurement practice influence operational performance as mean score value of all items under procurement practices is 2.99 which shows their disagreement regarding adequate management of procurement practices in the factory.Based on the reflection of results obtained from ADSF, ineffective control of supply and demand of inventory, inefficient continual stock replenishment and lack of regular reduction of production machine critically affects the operational performance of the factory resulting production stoppage which leads to high factory down time. Moreover, there are also ineffective Material requirements scheduling and lack of integration of supply chain in vendor managed inventory which are the reflections of poor inventory management as the mean score value of items raised under inventory management are: 2.54, 2.35, 2.42, 2.25, 2.37 and 2.24 respectively. As depicted in the result of descriptive analysis, respondents show their disagreement regarding the issue of using logistics information system which means applying computer based information system that support management of vehicle scheduling, inventory replenishment, etc., adequacy of Level of internal information sharing and Sharing of accurate information to all departments, having enough inter walk- talk radio that used to inform unexpected situation at factory operation through internally connected network within factory, investment on information Communication technology and making available up-to-date data to every departments which is shown in mean score value of item is up to 2.99 .

The descriptive analysis of the study also indicates that the respondents disagreed on adequate infrastructure for transportation of raw material inventory with in factory, scale of transportation infrastructure investment is sufficient, adequate Vehicle scheduling for transportation in the factory, adequate vehicle inspection schedule and sustainable appropriate preventive vehicle maintenance which is shown in mean score value of their responses $(2.17,2.32,2.17,2.32$ and 2.37 respectively). Warehousing means holding or preserving goods in huge quantities from the time of their purchase or production till their actual use or sale. The descriptive analysis of the study pinpoints respondent's disagreement on the issue of adequate goods acceptance process in factory, Suitable loading gates and in-house labels in warehouse, adequate automatic storage systems in factory, storage of inventory at right place, applying retrieval strategies such as first in-first out, last in-first out, quantity adaption, time phased, minimized aisle swaps, etc and having the fixed retrieval schedule for which the mean sore value of responses lies up to $2.99(2.42,2.20,2.52,2.32,2.17$ and 2.54 respectively).

\section{Correlation Analysis}

According to (Burns \& Burns, 2008) correlation Values between 0 and 0.3 (0 and -0.3) indicate a weak positive (negative) linear relationship via a shaky linear rule, Values between 0.3 and 0.7 (0.3 and -0.7) indicate moderate positive (negative) linear relationship and values between 0.7 and 1.0 (-0.7 and -1.0$)$ indicate a strong positive (negative) linear relationship via a firm linear rule as cited (Tiya, 2016). Therefore, in this study all correlation results are interpreted in light of this rule. In this regard, the relationship between the procurement practice and inventory, management, procurement practice and information flow, procurement practice and transportation, the procurement practice and operational performance and procurement practice and warehousing has moderate and strong positive relationship with correlation value of $0.608,0.425,0.367,0.677$ and 0.763 respectively. The relationship between inventory management and information flow, inventory management and transportation, inventory management and warehousing and inventory management and operational performance has moderate, moderate and strong, strong positive relationship with correlation value of $0.452,0.515,0.736$, and 0.755 respectively. The relationship between information flow and transportation, Information flow and warehousing and information flow and operational performance has moderate positive relationship with correlation value of $0,621,0.450$ and 0.658 respectively. The relationship between transportation and warehousing, transportation and operational performance has moderate and strong positive relationship with correlation value of 0.628 and 0.764 respectively. There is also strong positive relationship between warehousing and operational performance. The correlation value is 0.792

Regression Analysis

\begin{tabular}{|c|c|c|c|c|}
\hline \multicolumn{5}{|c|}{ Model Summary } \\
\hline Model & $\mathrm{R}$ & R-square & $\begin{array}{l}\text { Adjusted } \\
\text { R-Square }\end{array}$ & $\begin{array}{c}\text { Standard error of the } \\
\text { estimate }\end{array}$ \\
\hline 1 & $.912^{\mathrm{a}}$ & .831 & .827 & .21934 \\
\hline
\end{tabular}

As shown in table above, $83.1 \%$ of the variation in the operational performance was explained by the set of mentioned logistics practices. Conversely, adjusted R-squared provides an adjustment to the R-squared statistic such that an independent variable that has a correlation to dependent variable increases adjusted R-squared and any variable without a strong correlation will make adjusted R-squared decrease. Therefore, to see the success of our model in the real world adjusted R-squared is more preferred than R-squared (Burns, 2007). According to adjusted R-squared, the variation explained by the regression of dependent variable on the combined effect of all the predictor variables is $82.7 \%$. 


\begin{tabular}{|c|c|c|c|c|c|c|}
\hline \multicolumn{7}{|c|}{ ANOVA } \\
\hline \multicolumn{2}{|c|}{ Model } & Sum of square & Df & Mean square & $\mathrm{F}$ & Sig. \\
\hline \multirow[t]{3}{*}{1} & regression & 42.672 & 5 & 8.534 & 177.39 & $0.000^{\mathrm{b}}$ \\
\hline & Residual & 8.660 & 180 & .048 & & \\
\hline & Total & 51.331 & 185 & & & \\
\hline
\end{tabular}

As depicted in above ANOVA table, model is fit at significant of 0.000 .

\section{Summary, Conclusion and Recommendations}

A total of 219 questionnaires were distributed to employees of Arjo Didesa sugar factory working in Factory operation and Supply and Facility management department. From the distributed questionnaires, 186(84.99\%) were collected and all were used in the data analysis. The analysis result depicts that the mean score values for logistics practices dimensions are below the average mean value (only between 2.17 and 2.78) which indicates the logistics practice of Arjo Didesa sugar factory is inadequate. The study also found a positive correlation among the five logistics practices (procurement practice, inventory management, information flow, transportation and warehousing). Furthermore, the value of regression analysis shows that operational performance is explained by 0.268 and 0.244 , when there is a unit change in transportation management and inventory management respectively.

For clarity purpose, the conclusions are based on the research objectives of the study and recommendations are made to Ethiopia Sugar Corporation, Arjo Didesa sugar factory based on the findings of the study.

The study reveals that transportation management and inventory management very significantly influenced operational performance of Arjo Didesa sugar factory even though the other three logistics practices influence operational performance of the factory. As a result, the study concludes that logistics practices significantly influence firm's operational performance.

By relying on the study findings, the researcher initiated to provide the following recommendations for responsible body:

The human resource training and development programs of Arjo Didesa sugar factory are recommended to make assessment on the need and skill gap of the procurement staff and build the capacity of staffs and increase skills regarding supplier selection process, prequalification of suppliers and management of procurement process of the sugar factory in order to have adequate management of the procurement practice.

The researcher recommends that it is better if the Arjo Didesa sugar factory apply principle of economic order quantity that enable factory effectively control supply and demand of inventory, effective continual stock replenishment and effective material requirement scheduling because by applying principle of EOQ which let factory easily to know re-order point for continual stock replenishment, ordering optimum quantity according to material requirement scheduling which result in reduction of idle time of production machines for better inventory management which have great positive significant influence on operational performance of factory.

The study further recommends that it is worthwhile if the factory upgrade information technology infrastructure in order to make it easy and sufficient for every department to use automated inventory management, effective management of procurement process and smooth information flow through sharing accurate and up to date data to all departments within the factory. It is advisable if the factory improve infrastructure of transportation for raw material inventory within factory, vehicle scheduling for transportation, vehicle inspection schedule and preventive vehicle maintenance as these issues of transportation management are significantly influence the operational performance of the factory.

Researcher initiated to provide heartfelt recommendation to Ethiopia Sugar Corporation to consider the capacity of Arjo Didesa sugar factory while sending raw sugar collected from other sugar factories for refinery process as factory has no enough storage place as the result more than 20,000 quintals of sugar exposed to spoilage. It is worthwhile for the factory to give a critical emphasis on goods acceptance process, having suitable loading gates and in-house labels in warehouse, adequate automatic storage systems especially for storing raw material inventory and semi-finished goods, storing inventory at right place and arranging fixed retrieval schedule in order to have adequate warehousing which contributes positive significant influence on operational performance.

The study has provided greater insight into the logistics practice and operational performance of sugar manufacturing firm specifically Arjo Didesa sugar factory. This may aid in formulation of policies and regulations on the government part that can help to improve efficiencies and effectiveness in manufacturing sector especially sugar so as to boast supply of sugar product to meet highest domestic demand as well as earning higher currency through exporting to overseas market as this would be achieved through improving operational performance of the sugar factories in the country. Finally, further research on logistics practices or similar study areas are recommended to researchers. 


\section{Reference}

Annual report. (2016). Arjo Didesa Sugar Factory Annual Report.

Ashenaf. (2016). Capital Intensive Sugar Projects Still Bearing Fruit.

Cruijssen. F., Cools. M., \& Dollaert. W. (2007). Horizontal Cooperation in logistics: Opportunities and Pediments. Transportation Research Part. Logistics and Transportation Review, 4(2).

Dimitrios, P. (2008). The effect of inventory management on firm performance. International journal of productivity and performance management .

Donald, W. (2003). Logistics:An Introduction to Supply Chain Management. (M. S. Aardvark Editorial, Ed.) Palgrave Macmillan.

Emmett, S. (2005). Excellence in Warehouse Management How to Minimise Costs and Maximise Value.

Ethiopia investment agency. (2016). Investment opportunity profile for sugar platation and processing in Ethiopia.

Fekadu, M. D. (2013). Logistics Practices in Ethiopia.

Ghiani, Laporte, Musmanno. (2004). Introduction to Logistics Systems Planning and Control.

Kedir, H. S. (2013). Value Chain Analysis Focusing on Organizational Production Process: The Case of Wonji/Shoa Sugar Factory. Jimma, Management.

Kiare, K. M. (2015). Influence ofProcurement practices on organization performance in private sector in Kenya. International Journal of Business \& Law Research, 3(2).

Lipaj, D., \& Davidaviciene, V. (2013). Influence of Information Systems on Business Performance. journal of Business Management, 5(1), 38-45.

Miller, R. (2008). International Political Economy: Contrasting World Views. pp. 216-236.

Moore, R. (1998). Theory of Constraints and Lean Manufacturing.

Mokogi; Mairura; \& Ombui. (2015). Effects of Procurement Practices on the Performance of Commercial State Owned Enterprises in Nairobi County. International Journal of Scientific and Research Publications, 5(6).

Mukolwe, G. A. (2015). An Assessment of the Effect of Logistics Management on Operational Effiency at Mumias Sugar Company Limited, Kenya. International Journal of Economics, Commerce and Management .

Mwangangi, P. W. (2016). Influence of Logistics Management on Performance of Manufacturing Firms in Kenya.

Nyabwanga, \& Ojera. (2012). Inventory management practices and business performance for small-scale enterprices in Kenya. Journal of business management.

Peteraf, M., \& Barney, J. (2003). Unraveling the resource-based tangle. journal of Managerial and Decision Economics, 24(4).

Shang, K.-C., \& Marlow, P. B. . (2007). The effects of logistics competency on performance. Journal Of International Logistics And Trade.

W. Mwangi \& T. Nyambura . (2015). The Role of Inventory Management on Performance of Food processing of Companies: A Case Study of Crown Foods Limited kenya. European Journal of Business and Social Sciences, 4(04).

Wisner, Tan \& Leong. (2012). Principles of Supply Chain Management (Third edition ed ed.). 